\title{
Experimental Study of Tensile Properties of the Steel-Plastic Geogrids
}

\author{
Qingbiao Wang ${ }^{*}, 1,2,3$, Rongshan $\mathrm{Lü}^{1}$, Yingchun Kong ${ }^{1}$, Lei Xu ${ }^{1}$ and Cong Zhang ${ }^{1}$ \\ ${ }^{I}$ College of Civil Engineering and Architecture, Shandong University of Science and Technology, Qingdao Shandong \\ 266590, China \\ ${ }^{2}$ Department of Resource and Civil Engineering, Shandong University of Science and Technology, Taian, Shangdong \\ 271019, China \\ ${ }^{3}$ Shandong Hualian Mining Co., Ltd., Yiyuan, Shangdong, 256119, China
}

\begin{abstract}
Tensile strength is an important indicator of the steel-plastic geogrid mechanical properties. Tensile strength directly affects the size of the steel geogrid security and stability in support of the project. Stretching through the indoor geogrid test for combinations of different sizes and different geogrid elongation rate, tensile strength of the geogrid were compared. The findings are as follows: (1)The size of the stretching rate has a significant effect on the tensile properties of steel-plastic geogrid. The strain is constant, the stretching rate, the lower the tensile strength of the geogrid; stretching rate is constant, the greater the strain Plastic geogrid, the greater the tensile strength;(2) Peak strain increases with extension rates decrease; higher tensile strength material to reduce the amplitude of the smaller; under the same conditions of stretch rate, the lower the tensile strength of the geogrid, the higher the peak strain;(3)Different effects under different specifications geogrid tensile rate, steel-plastic geogrid degree of influence by the stretching rate is less than the plastic geogrid.
\end{abstract}

Keywords: Tensile modulus, tensile property, the steel-plastic geogrid, tensile strength.

\section{INTRODUCTION}

Geogrid for its advantages of high strength, good durability, to facilitate construction has been widely used in the highways, railways, and mine fields. As the reinforcement material, it can be applied to the supporting structure, mainly through the tensile strength to bear the load of soil.

In the past, researchers have only studied the tensile properties of geosynthetics. Moraci [1] studied the method of the pullout resistance of geogrids. Hou J [2] studied the pullout test of bidirectional geogrid with strengthen nod. Cai Chun, Zhang Mengxi [3] studied reinforced reinforcement soil interface properties of the rib of geogrid by lots of pullout experiments, and discussed factors affecting the ultimate pullout resistance, and deduced the theory formula of pullout resistance. Shi Youzhi, Ma Shi Dong [4] evaluate the interfacial friction coefficient between geogrid and sand gravel, coarse sand, residual soil by geogrid interface characteristic experiments. Luan Maotian, Xiao Chengzhi [5] studied the creep properties of geogride on different combinations between load and and temperaturetest through the indoor creep test, and proposed constitutive model of viscoelastic creep properties of geogrids. Yang ye, Liu Songyu [6] studied new technology method on testing geogrid stress condition, and found that the electric induction

*Address correspondence to this author at the Department of Resource and Civil Engineering, Shandong University of Science and Technology, Taian, Shangdong 271019, China; Tel: +8618805381111 ;

E-mail: 1349725165@qq.com measurement of displacement of geogrid was accurate and reliable. Wu Jinghai [7] studied the geosynthetic interface properties by pullout test, and found that: the drawing coefficient of warp knitting geogrid was higher than plastics geogrids, geosynthetics was the lowest. GaoJie [8] investigated the tensile mechanism of geogrid, and studied the effect that geogrid tensile process conditions on the performance of the geotechnical grille.performance of the geotechnical grille. Yang Guangqing, Lv Peng [9] studied the plastic geogrid tensile properties through the tension test.

In recent years, although the new model reinforcement material, the steel-plastic geogrid were widely used in reinforced soil engineering, but the corresponding experimental research carried out is not many, and many factors would influence the tensile properties of geogrid. Therefore, the tensile tests were carried out in the plastic geogrid, it is necessary to study that how the tensile rate influence the geogrid in the tension test.

\section{THE STEEL-PLASTIC GEOGRID OVERVIEW}

\subsection{Concept and Scope of Application}

The steel-plastic geogrid that is based on plastic geogrid, is made of high strength steel wire and PE or PP and other additives. Steel wires are wrapped by PE or PP by special fusing, then these form compound high strength tensile band with surface roughness by extrusion, followed longitudinal and transverse. The junction points of geogrid are bonded by using special welding technology. Changing the diameter of steel wire and quantity improve the tensile strength of geogrid. The steel-plastic geogrid can enhance tensile 
strength of geogrid, improve to resist creep properties, and prolong the service life of the grid, which is suitable for coal mine, highway, railway, airport, well irrigation, civil construction and so on Fig. (1) is the steel-plastic geogrid.

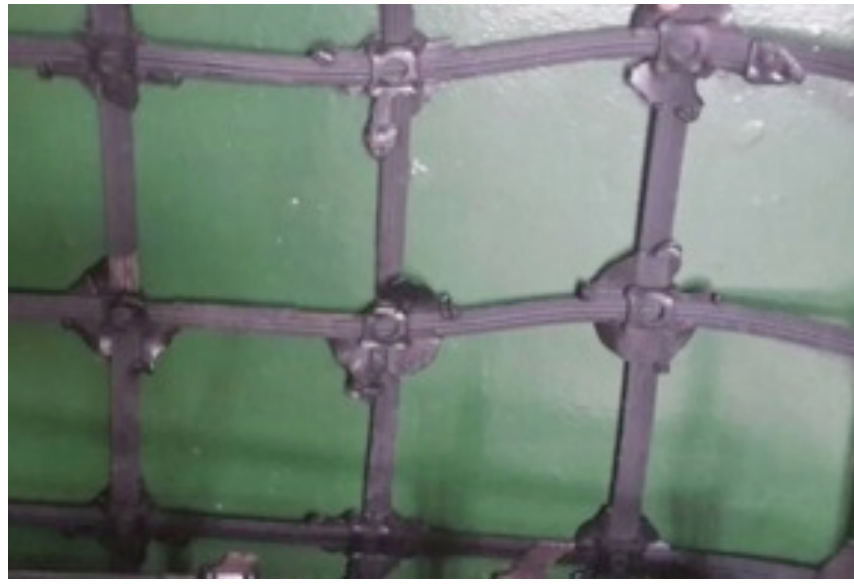

Fig. (1). The steel-plastic geogrid.

\subsection{Production Process}

1. According to the production of the product specifications, It is mixed with new PE raw materials and recycling of material particles; According to the size of the peeling force, it is mixed the new material and recycling materials; then measurement;

2. After mixture, We use the mixing machine to mix raw materials; then artificial mixing and blending, according to the requirements and add master batch, defoaming agent and other accessories, mixing;

3. Feeding, mixed PE material, add extruder, and preheating the extruder;

4. According to strip tension wire size, we calculate quantity of steel wire, and place steel wire in wire frame;

5. We use an extruder to heat the material of PE, and high temperature make PE become harmonious state, Steel wire are closely arranged in a mould, and are packaged by melting PE. Then soak it in ice water to cool rapidly. Extrusion, condensation, forming.

6. Geogrid welding, place the geogrid on the high frequency welding machine to weld by ultrasonic welding.

\section{THE STEEL-PLASTIC GEOGRID TENSILE CHARACTERISTIC INDEX}

The tensile strength is the most important index, when geogrides are applied to the mine roadway supporting structure. It is represented by the tension of unit length, and the unit is $\mathrm{KN} / \mathrm{m}$ or $\mathrm{N} / \mathrm{m}$. The tensile strength of geogrids test is easily influenced by outside factors, such as the length and width of the sample, shape, test fixture and external factors, so the test must be on in the standard conditions according to the specification.
Elongation is another main indicator of the steel-plastic geogrid. It is a percentage of elongation accounted for the original length:

$\delta=\Delta L / L$

$\Delta \mathrm{L}$ is the changes in length of geogrids, $\mathrm{L}$ is the original length. In the experiment, we can obtain experimental data to calculated Elongation directly. The second method is that we can draw elongation curves to calculate. The tensile modulus is generally refers to a certain tension within the scope of the modulus. Because the geogrid stress-strain curve is usually nonlinear, so geogrid tensile curves have different shapes that lead to the method to determine the tensile modulus is different.

\section{EXPERIMENT TENSILE PROPERTIES OF STEEL- PLASTIC GEOGRID}

The laboratory test is an important way which in analyzing engineering properties of working stress state of soil structure with geo-grid reinforced, It is very important to how to effectively analyze tensile properties of soil structure with geo-grid reinforced. The present method is mainly based on according to various standards or specifications, and using the various parameters of the specification which were determined by acertain tensile rate in tensile test conditions.

\subsection{Test Preparation}

In order to study the tensile properties of geogrids under the different tensile rates, we will select 3 kinds of different specifications of steel plastic geogrid which in the uniform and different strain rates $(50,10,1,0.1,0.05 \mathrm{~mm} / \mathrm{min})$ tensile test research. Test instrument is universal material testing machine which name is DR028J, as shown in Fig. (2). The main technical specifications of 3 types of geo-grid as shown in Table $\mathbf{1}, \mathrm{A}$ is a bidirectional plastic geogrid, $\mathrm{B}$ and $\mathrm{C}$ are the two-way steel plastic geo-grid. The test $(20 \pm 2)^{\circ} \mathrm{C}$ in constant temperature and $(60 \pm 5) \%$ relative humidity conditions, which use the fixture to clamp the steel-plastic geogrid by the universal testing machine, as shown in Fig. (3), and use the numerical control universal testing machine to control the whole test.

From Fig. (4), it is clear that the type A of geogrid during the stretching process, the displacement of the grid deformation is gradually increasing as load increases, the tensile curve is on the rise, when tension is $5.9 \mathrm{KN}$, the tensile curve decrease rapidly, load decreases rapidly to zero, it is clear show that the grille has been broken, the tensile strength reduces to zero. As can be seen from Fig. (4). The displacement in type A geogrid which is proportional to the tensile strength before the tensile strength limit of the grille is reached.

Table 2 show: when tensile rate decreased from 50 $\mathrm{mm} / \mathrm{min}$ to $0.05 \mathrm{~mm} / \mathrm{min}$, the tensile strength and tensile modulus of type A geogrid decreased by $20.02 \%$ under $2 \%$ strain conditions; the tensile strength and tensile modulus of $\mathrm{B}$ reduced by $19.03 \%$ under the conditions of $5 \%$ strain; on the contrary, geogrid peak strain increased by $23.36 \%$. 
Table 1. Main index of the geogrids in test.

\begin{tabular}{|c|c|c|c|}
\hline \multirow{2}{*}{ Type } & \multicolumn{3}{|c|}{ Type and Specification } \\
\hline & A & $\mathbf{0 . 7 m m}$ & $\mathbf{0 . 7 m m * 1 2}$ \\
\cline { 2 - 4 } & $\geqq 105.0$ & $\geqq 128.0$ & $\mathbf{0 . 7 m m * 1 8}$ \\
\hline \hline Vertical (horizontal) totensile strength $(\mathrm{KN} / \mathrm{m})$ & $\geqq 25.2$ & $\geqq 30.4$ & $\geqq 38.5$ \\
\hline The tensile strength of the $2 \%$ longitudinal strain $(\mathrm{KN} / \mathrm{m})$ & $\geqq 49.8$ & $\geqq 61.2$ & $\geqq 76.5$ \\
\hline The tensile strength of the $5 \%$ longitudinal strain $(\mathrm{KN} / \mathrm{m})$ & $\leqq 15.5$ & $\leqq 15.5$ & $\leqq 15.5$ \\
\hline Peak strain/\% & & & \\
\hline
\end{tabular}

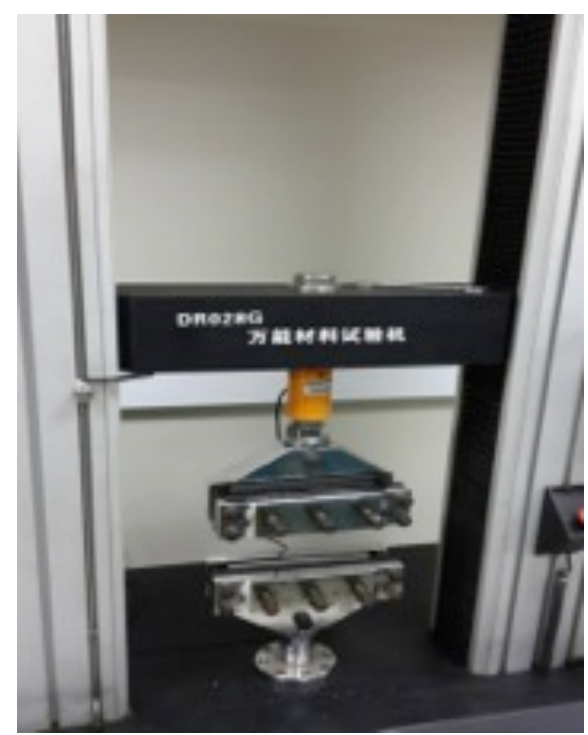

Fig. (2). Universal material testing machine.

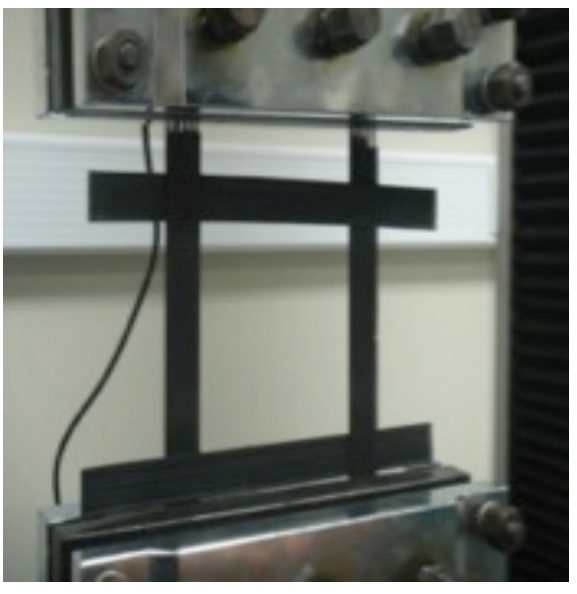

Fig. (3). Universal material testing tensile geogrids.

\subsection{The Results of Tensile Test}

\subsubsection{The Results of Tensile Test on Type A}

Seen from Fig. (5), the tensile process of type B geogrid can be divided into 3 stages: low load-large deformation stage, high load-small deformation stage, fracture stage. In the process of starting load, which is the low load-large deformation stage: tensile load is small, the displacement of the tensile deformation is larger, the diplacement eventually reach $19.2 \mathrm{~mm}$; and then entered the second phase high load small deformation stage: at this stage, the displacement of the grid deformation is gradually increasing as load increases, as can be seen from the graph, The large rise in the tensile curve, but in the same load difference, the amplitude of displacement variation in the second stage is smaller than the first phase, and it's just only $6 \mathrm{~mm}$; That's the third phase(fracture stage)when the load reaches $12.29 \mathrm{KN}$ : in this phase, the steel wire in grille band break one after another, which tensile curve sharp decline. The tensile strength is also rapidly reduced to 0 . From the analysis we can see: the tensile strength of type B geogrid by large impact of steel wire, the tensile strength of grid reaches minimal after the steel wire breakage.

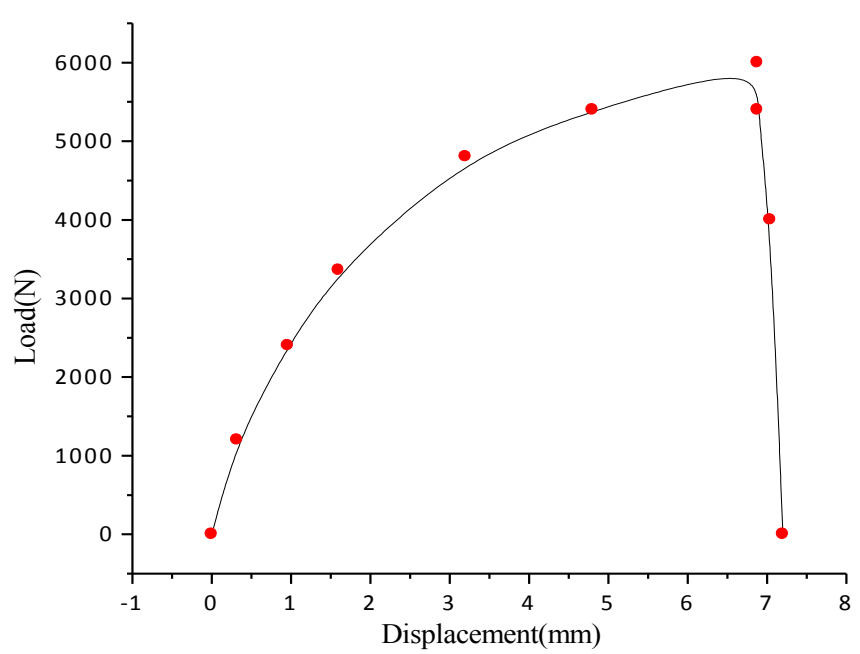

Fig. (4). Tensile test result of A geogrids at a steady speed.

\subsubsection{The Results of Tensile Test on Type B}

As we can see from Table 3 : when tensile rate decreased from $50 \mathrm{~mm} / \mathrm{min}$ to $0.05 \mathrm{~mm} / \mathrm{min}$, the tensile strength and tensile modulus of type A geogrid is decreased by $18.08 \%$ under $2 \%$ strain conditions; the tensile strength and tensile modulus of $\mathrm{B}$ is reduced by $16.67 \%$ under the conditions of $5 \%$ strain; on the contrary, geogrid peak strain increased by $20.52 \%$.

Seen from Fig. (6), the stretching process of type $\mathrm{C}$ geogrid is similar to type $\mathrm{C}$ geogrid, and this process can be divided into two stages: tensile stage and silking stage. the tensile displacement is gradually increasing as tensile load increases before the tensile strength limit of the grille is 
Table 2. Tensile test result of A geogrid at a different speed.

\begin{tabular}{|c|c|c|c|c|c|c|}
\hline \multirow{2}{*}{ Type } & \multirow{2}{*}{$\begin{array}{l}\text { Tensile Rate } \\
\text { (mm/min) }\end{array}$} & \multicolumn{2}{|c|}{$2 \%$ Strain } & \multicolumn{2}{|c|}{$5 \%$ Strain } & \multirow{2}{*}{$\begin{array}{c}\text { Peak } \\
\text { Strain/\% }\end{array}$} \\
\hline & & Tensile Strength $(\mathrm{KN} / \mathrm{m})$ & Tensile Module (KN/m) & Tensile Strength $(\mathrm{KN} / \mathrm{m})$ & Tensile Modulus (KN/m) & \\
\hline A & 50 & 30.56 & 986.96 & 60.43 & 790.4 & 10.76 \\
\hline A & 10 & 27.98 & 963.9 & 54.77 & 773.0 & 11.32 \\
\hline A & 1 & 26.54 & 942.5 & 52.09 & 751.8 & 11.96 \\
\hline A & 0.1 & 25.73 & 869.0 & 50.10 & 694.2 & 12.54 \\
\hline A & 0.05 & 24.44 & 822.3 & 48.93 & 663.7 & 13.27 \\
\hline
\end{tabular}

Table 3. Tensile test result of $B$ geogrids at a different speed.

\begin{tabular}{|c|c|c|c|c|c|c|}
\hline \multirow{2}{*}{ Type } & \multirow{2}{*}{$\begin{array}{c}\text { Tensile Rate } \\
(\mathbf{m m} / \mathbf{m i n})\end{array}$} & Tensile Strength (KN/m) & Tensile Module (KN/m) & Tensile Strength (KN/m) & Tensile Modulus (KN/m) & Peak \\
\cline { 3 - 7 } & & 50 & 48.67 & 1770.7 & 93.45 & 1279.1 \\
\hline \hline B & 10 & 44.31 & 1701.4 & 85.56 & 1202.3 & 10.07 \\
\hline B & 1 & 41.69 & 1639.0 & 79.65 & 1146.7 & 1103.2 \\
\hline B & 0.1 & 40.95 & 1546.5 & 79.01 & 11.25 \\
\hline B & 0.05 & 39.87 & 1499.6 & 77.87 & 11.76 \\
\hline
\end{tabular}

reached, and the relationship between them are Proportional, When the tension reaches $17.28 \mathrm{KN}$, the polyethylene will be separated from the steel wire in the steel-plastic grille, at this time the silking phenomenon of the steel plastic grille appeared in the fixture, steel wire tension has not yet express its full potential, resulting in curve drops rapidly and strength decreases gradually after the tension of the steel-plastic geogrid reaches a certain strength.

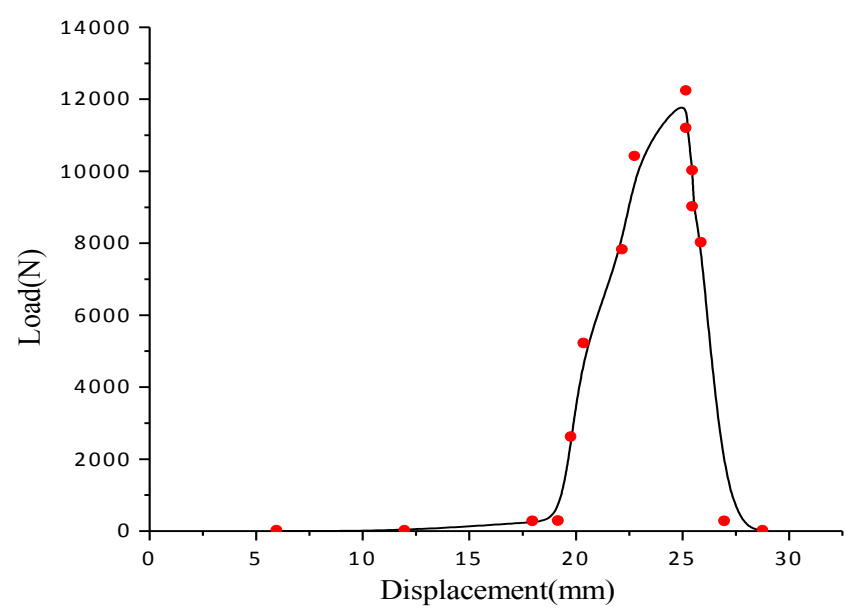

Fig. (5). Tensile test result of B geogrid at a steady speed.

\subsubsection{The Results of Tensile Test on Type C}

As we can see from Table 4: when tensile rate decreased from $50 \mathrm{~mm} / \mathrm{min}$ to $0.05 \mathrm{~mm} / \mathrm{min}$, the tensile strength and tensile modulus of A typical geogrid is decreased by $12.82 \%$ under $2 \%$ strain conditions; the tensile strength and tensile modulus of $\mathrm{B}$ is reduced by $15.67 \%$ under the conditions of $5 \%$ strain; on the contrary, geogrid peak strain increased by $17.79 \%$.

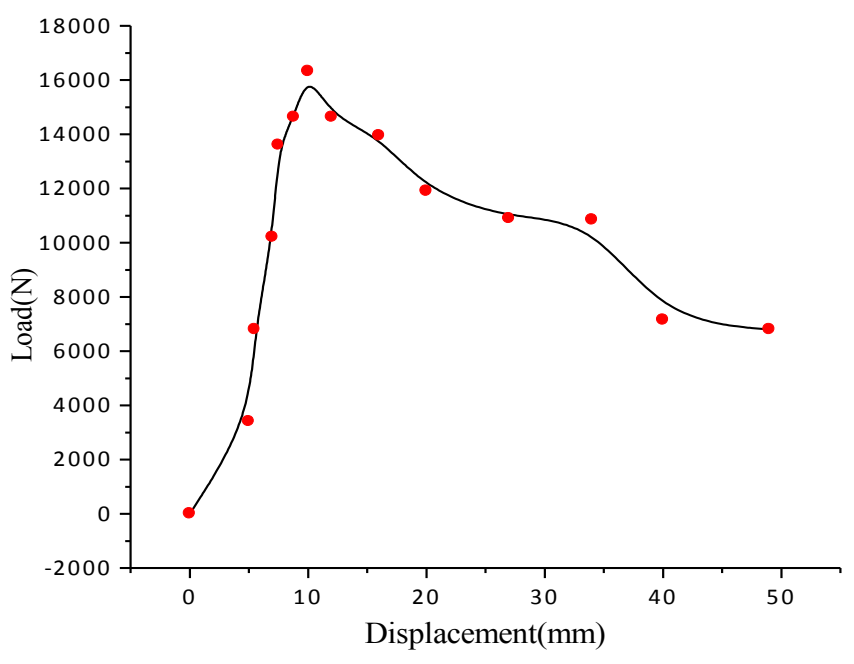

Fig. (6). Tensile test result of $\mathrm{C}$ geogrids at a steady speed.

\section{THE RESULT ANALYSIS}

At the beginning of drawing steel-plastic geogrid, the viscidity of geogrids and fixtures is pretty strong. With the growth of resistance, the tensile modulus of whole mould will be growing. With the growth of the drawing, the viscidity of geogrid will be shown more clearly. The geogrids will show a various kinds or types breaks when the drawing get a certain point. Type A of geogrid is pulled off when the tension value reaches $5.9 \mathrm{KN}$; When the tension value reaches $12.29 \mathrm{KN}$, type B of geogrid's steel wires are pulled off one by one, then the tensile strength decreases rapidqly; When the tension value reaches $17.8 \mathrm{KN}$, type C of geogrid's steel wire are drawn out from the polyethylene coated layer, the emergence of wire 
Table 4. Tensile test result of $\mathrm{C}$ geogrids at a different speed.

\begin{tabular}{|c|c|c|c|c|c|c|}
\hline \multirow{2}{*}{ Type } & \multirow{2}{*}{$\begin{array}{c}\text { Tensile Rate } \\
(\mathbf{m m} / \mathbf{m i n})\end{array}$} & Tensile Strength (KN/m) & Tensile Module (KN/m) & Tensile Strength (KN/m) & Tensile Modulus (KN/m) & Peak \\
\cline { 3 - 7 } & & 50 & 50.78 & 2562.1 & 81.69 & 2031.2 \\
\hline \hline C & 10 & 49.22 & 2477.6 & 78.13 & 1965.6 \\
\hline C & 1 & 46.25 & 2364.0 & 76.47 & 10.42 \\
\hline C & 0.1 & 45.43 & 2271.4 & 75.96 & 1877.0 & 1754.3 \\
\hline C & 0.05 & 44.27 & 2208.2 & 68.89 & 11.23 \\
\hline
\end{tabular}

drawing. Strength decreases gradually. But type C geogrid doesn't reach the ultimate tension.

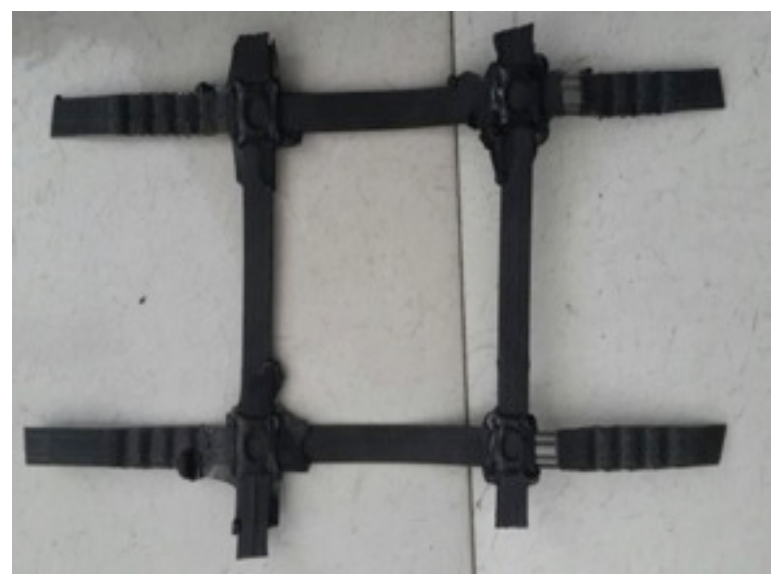

Fig. (7). $0.7 * 12$ steel-plastic geogrid.

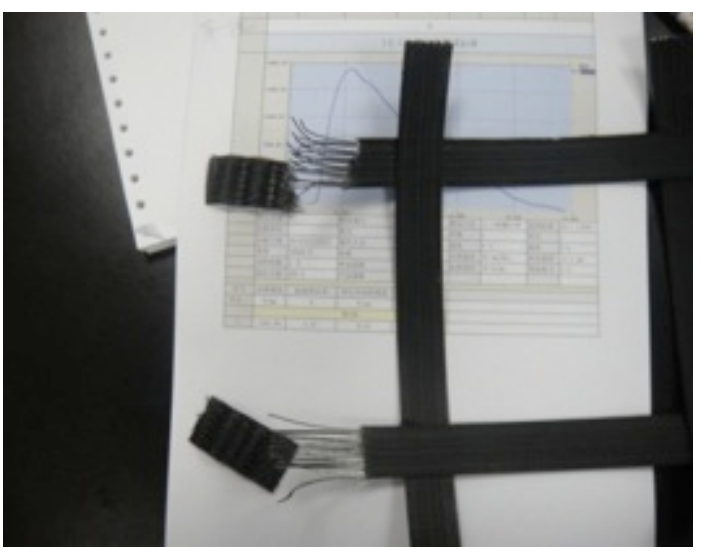

Fig. (8). $0.7 * 18$ steel-plastic geogrid.

(2) When the tensile rate decreased from $50 \mathrm{~mm} / \mathrm{min}$ to $0.05 \mathrm{~mm} / \mathrm{min}$, three different typies of geogrids tensile strength respectively decreased by $20.02 \%$, $18.08 \%, 12.82 \%$ under $2 \%$ strain condition; under $5 \%$ strain condition, three different typies of geogrids tensile strength respectively decreased by $19.03 \%, 18.13 \%, 15.67 \%$. It is clear that the type A geogrids decreased furthest, and type B is the second, and type $\mathrm{C}$ is the minimum. The reason is that: type $\mathrm{A}$ geogrid is plastic geogrid without steel wire; type B and type $\mathrm{C}$ are the steel-plastic geogrid and contain a certain amount of steel wire.

(3) When the tensile rate decreased from $50 \mathrm{~mm} / \mathrm{min}$ to $0.05 \mathrm{~mm} / \mathrm{min}$, the peak strain of three different typies of geogrids respectively increased by $23.36 \%$, $20.52 \%, 17.79 \%$. The peak strain decreases with the increase of tensile rate; the higher tensile strength is, the smaller decreasing amplitude is; in the same tensile rate, the lower tensile strength of geogrids is, the higher the peak strain will be. Fig. (9) is the curve of peak strain and tensile speed.

(4) When the tensile rate is $50 \mathrm{~mm} / \mathrm{min}$, the corresponding tensile strength type A of geogrid are respectively $30.56 \mathrm{KN} / \mathrm{m}$ and $60.43 \mathrm{KN} / \mathrm{m}$ under $2 \%$ and $5 \%$ strain condition, the tensile modulus were $1187.6 \mathrm{KN} / \mathrm{m}$ and $983.4 \mathrm{KN} / \mathrm{m}$; under same condition, the corresponding tensile strength type $\mathrm{B}$ of geogrid are respectively $48.67 \mathrm{KN} / \mathrm{m}$ and $93.45 \mathrm{KN} / \mathrm{m}$, the tensile modulus were $2038.5 \mathrm{KN} / \mathrm{m}$ and $1339.1 \mathrm{KN} / \mathrm{m}$; the corresponding tensile strength type $\mathrm{C}$ of geogrid are respectively $50.78 \mathrm{KN} / \mathrm{m}$ and $81.69 \mathrm{KN} / \mathrm{m}$, the tensile modulus were $2562.1 \mathrm{KN} / \mathrm{m}$ and $2031.2 \mathrm{KN} / \mathrm{m}$. Obviously, for a particular stretch rate the same kind of geogrid, under $2 \%$ and $5 \%$ strain condition and peak strain corresponding the tensile strength increases, while the tensile modulus decreases in turn. For a same geogrid, the higher tensile rate is, the smaller the tensile modulus.

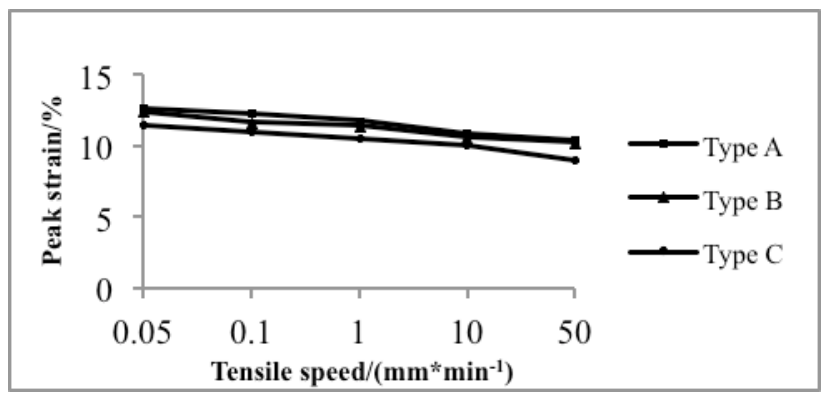

Fig. (9). The curve of peak strain and tensile speed.

\section{DISCUSSION}

The tensile experiment is based on the assumption that the whole experiment could be made under the normal temperature and the materials which geogrids made of are same. But in reality, the working environment of soil engineering geogrids is not always in normal temperature and the materials made of geogrids are not always same. Based on these two assumptions, the experiment is different from real project. In real project, engineerings of inflexibility geogrids are made underground and differences in temperature are small. As much as the tensile experiment is 
simple but it is related to the reality, which made it pretty useful and helpful in engineering.

\section{CONCLUSION}

(1) For a kind of geogrid, the size of the stretching rate has a significant effect on the tensile properties of steel-plastic geogrid. When the strain is a certain value, the faster tensile rate is, the lower the tensile strength of geogrid will be; when the tensile rate is a certain value, the greater the steel-plastic geogrid is, the higher the tensile will be.

(2) With the increase of tensile rate, the peak strain decreases gradually; The higher the tensile strength is, the smaller decreasing amplitude of the peak strain is; when the tensile rate is a certain value, the In the same strain rate, the lower the tensile strength of geogrids is, the higher the peak strain would be.

Different effects under different specifications geogrid tensile rate, steel-plastic geogrid degree of influence by the stretching rate is less than the plastic geogrid; the more steel quantity the steel-plastic geogrid contains, the stronger tensile strength is, and the smaller it is affected by the degree of tensile rate, the tensile strength and tensile modulus of geogrids will reduce with the decrease of stretching rate and tensile modulus of the same geogrids will increase with the raise of stretching rate.

\section{CONFLICT OF INTEREST}

The authors confirm that this article content has no conflict of interest.

\section{ACKNOWLEDGEMENTS}

This work was financially supported by:

(1) National Natural Science Foundation of China(NSFC) (41372289, 51409154);

(2) SDUST Research Fund

(3) A Project of Shandong Province Higher Educational Science and chnology Program (12LH03);

(4) China's Post-doctoral Science Fund (2012M521365).

\section{REFERENCES}

[1] Moraci N, Gioffre D.A simple method to evaluate the pullout resistance of extruded geogrids embedded in a com pacted granular soil [J]. Geotextiles and Geomembranes, 2006,24(2):116-128.

[2] Hou J, Zhang M X, Javadi A A, et al. Experiment and analysis of strength behaviour of soil reinforced with horizontal-vertical inclusions[J]. Geosynthetics International, 2011,18(4):150-158.

[3] Cai Chun, ZHANG Meng-xi, et al. Pull-out test of uniaxial geogrid with strengthening ribs[J]. Rock and Soil Mechanics, 2012.33(1):53-60.

[4] Shi You-zhi, MA Shi-dong. Test for interface characteristics of geogrid[J]. Rock and Soil Mechanics, 2003,24(2): 22-24.

[5] Luan Mao-tian, XIAO Cheng-zhi, YANG Qing, et al. Experimental study on creep properties and viscoelasticity constitutive relationship for geogrids[J].Rock and Soil Mechanics, 2005, 26(2): 187-192.

[6] Yang Ye, LIU Song-yu, et al. New measuring technology of geogrids under load[J].Chinese Journal of Geotechnical Engineering,2009,31(7):1133-1137.

[7] Wu Jing hai. Study on interaction characteristics between geosynthetics and fill materials by pull out tests[J]. Rock and Soil Mechanics, 2006, 27(4): 581-585.

[8] Gao Jie. Study on Stretch Mechanism and Process Conditions in Drawing Geogrid $[\mathrm{J}]$. Journal of Beijing In stitute of Petroehemieal Teehnology, 2002,10(2):28-31.

[9] Yang Guang-qing, PANG Wei, LÜ Peng. Experimentalb study of tensile properties of geogrids[J]. Rock and Soil Mechanics, 2008, 29(9): $2387-2391$.

(C) Wang et al.; Licensee Bentham Open.

This is an open access article licensed under the terms of the Creative Commons Attribution Non-Commercial License (http://creativecommons.org/licenses/ by-nc/3.0/) which permits unrestricted, non-commercial use, distribution and reproduction in any medium, provided the work is properly cited. 